\title{
Endophytic selenobacteria and arbuscular mycorrhizal fungus for Selenium biofortification and Gaeumannomyces graminis biocontrol
}

\author{
Paola Durán $^{1 *}$, Sharon Viscardi ${ }^{3}$, Jacquelinne J. Acuña ${ }^{1}$, Pablo Cornejo ${ }^{1}$, Rosario Azcón ${ }^{2}$ \\ María de la Luz Mora ${ }^{1}$
}

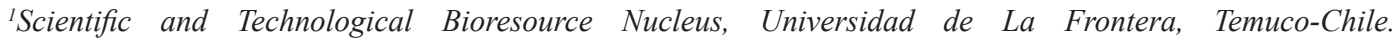
${ }^{2}$ Departamento de Microbiología del Suelo y Sistemas Simbióticos, Estación Experimental del Zaidin (CSIC), Granada-Spain. ${ }^{3}$ Departamento de Procesos Diagnósticos y Evaluación, Facultad de Ciencias de la Salud, Universidad Católica de Temuco, Temuco, Chile *Corresponding author: paola.duran@ufrontera.cl

\begin{abstract}
Selenium (Se) is an important antioxidant considered among the fertilization programs in developed countries. In Chile, chemical fertilization based in Se is inefficient due the physicochemical characteristics of Andisol that sustain the $60 \%$ of crop production. Andisol also are highly conductive to take-all disease caused by Gaeumannonyces graminis var tritici (Ggt). Here, we evaluated the effect of Bacillus sp.E5 and Acinetobacter sp.E6.2 and Claroideoglomus claroideum as potential inocula for Se biofortification and Ggt bicontrol in wheat. Plants inoculated with Acinetobacter sp.E6.2 showed major root growth and major Se content in shoots and grains. The antioxidant role of Se regarding DPPH activity was shown in Se-supplemented plants with small Se nanoparticles founded inside the roots. Mycorrhizal plants showed major SOD activity in shoots but no affected the Se uptake. Respect to pathogen biocontrol, plants inoculated with both bacteria showed an efficient control against Ggt independent to mycorrhization. Thus, our inocula could make important contributions to produce enriched Se flours for human nutrition and biocontrol against Ggt.
\end{abstract}

Keywords: Selenium, biofortification, Green Fluorescent Protein, NanoSe, take-all disease

\section{Introduction}

In recent years, several studies relating to the role of selenium ( $\mathrm{Se}$ ) in human health have been conducted because Se plays an essential antioxidant function in glutathione peroxides (GSH-Px), production of selenoproteins for antioxidant defence systems, inhibition of DNA damage and cancer prevention and progression (Xu et al., 2003). However, the level of Se intake worldwide is inadequate for the expression of important selenoproteins (Rayman, 2007). In developed 
countries such as Finland and Australia, agronomic biofortification by the addition of inorganic Se to soil is commonly applied (Lyons et al., 2003). In Chile, this technology is inappropriate because in our Andisol, inorganic Se forms sodium selenite and is bound to soil constituents such as clays and oxy-hydroxides of aluminium $(\mathrm{Al})$, iron $(\mathrm{Fe})$ or manganese $(\mathrm{Mn})$, remaining unavailable to plants (Mora et al., 2008), whereas sodium selenate can be leached during wet fall conditions (Govasmark and Salbu, 2011). Thus, while Se content in soils of the South of Chile is low, ranging between 21 and $180 \mu \mathrm{g} \mathrm{kg}^{-1}$ (Cartes et al., 2005) there are not viable strategies for Se fertilization. In addition, the mineralogical compositions of the Andisol provide limited conditions for root development; therefore, a decrease in plant performance is commonly observed (Mora et al., 2008).

Studies previously conducted by our research group showed that microorganisms, such as selenobacteria, can metabolize and transform inorganic Se into nanospheres of elemental Se (NanoSe) (Acuña et al., 2009) and other organic Se forms. These Se forms can enhance the Se content in wheat plants through biofortification strategies based on efficient inoculation of rhizospheric bacteria with arbuscular mycorrhizal fungi (AMF) (Durán et al., 2013). In a recent study, we showed that the plant growth promoting (PGP) endophytic bacteria Bacillus sp.E5 and Acinetobacter sp.E6.2 have more important ecological advantages than rhizospheric bacteria in terms of $\mathrm{Se}$ tolerance and Gaeumannomyces graminis biocontrol (Durán et al., 2014) due to endophytic microorganisms can produce antifungal metabolites. In recent studies, Bacillus sp.E5 and Acinetobacter sp.E6.2 were able to produce Se organic forms, such as seleno-methyl-selenocysteine (SeMeSeCys) and seleno-methionine (SeMet) (Durán et al., 2015), which can play a role in cancer prevention (Rayman, 2007).
On the other hand, Gaeumannomyces graminis is a soil borne pathogen that affect wheat plant in Chile, causing losses around $50 \%$ of wheat production due to environmental and agronomic conditions as monoculture (Duran et al., 2017, 2018). However, further research involving agricultural plant species and using these endophytic bacteria and AMF are needed to elucidate their role in Se biofortification and Gaeumannomyces graminis biocontrol.

Here, we hypothesized that endophytic bacteria could serve for Se augmentation inside the plant because bacteria can incorporate NanoSe into the cells and could have a synergic effect with mycorrhiza improving the antioxidant system and plant growth. Thus, the main objective of this study was to evaluate the efficiency of these microbial association in terms of Se increase, the antioxidant activity in plants and the capacity of biocontrol of Gaeumannomyces graminis. In addition, we studied the ability of NanoSe to enter plant cell and the endophytic capacity of bacteria inocula. Our results may be useful for the consideration of novel selenium biofertilizer with capacity of biocontrol of the main pathogen that affect the most consumed cereal in Chile and can to serve of basis to incorporate this important antioxidant inside the fertilization strategies.

\section{Materials and Methods}

\subsection{Inocula preparation}

\subsubsection{Bacteria inococula preparation}

Two previously isolated endophytic selenobacteria strains identified as Acinetobacter sp.E6.2 and Bacillus sp.E5 (Durán et al., 2014) were used for inocula preparation. The isolates are deposited at the Chilean Culture Collection of Type Strains 
(CCCT/UFRO), which is registered at the World Federation of Culture Collection under the number WDCM1111 and is hosted at the Scientific and Technological Bioresource Nucleus (BIOREN) from Universidad de La Frontera, Temuco, Chile with the codes: CCT 15.25 (Acinetobacter sp.E6.2) and CCT 15.23 (Bacillus sp.E5).

Strains were grown in $200 \mathrm{~mL}$ of Luria Bertani media (LB) supplemented with $5 \mathrm{mM}$ sodium selenite $\left(\mathrm{Na}_{2} \mathrm{SeO}_{3}\right.$, Merck, Inc.) according to Durán et al., (2013). After growth at $30^{\circ} \mathrm{C}$ for $24 \mathrm{~h}$ with continuous shaking $(150 \mathrm{rpm})$, the bacterial cells were collected by centrifugation at $10,000 \mathrm{x}$ g for $10 \mathrm{~min}$ and rinsed twice with sterile saline solution $(0.85 \% \mathrm{NaCl})$. The bacterial cell suspension was used as a selenobacteria inoculum for greenhouse experiments.

\subsubsection{Mycorrhizal propagation}

Claroideoglomus claroideum (N.C. Schenck \& G.S. Sm.) C. Walker \& A. Schüßler, isolated from the rhizosphere of wheat plants growing in volcanic soils from Southern Chile was used for plant mycorrhization. For the Claroideoglomus claroideum (AMF) inoculum preparation, Sorghum bicolor plants cv Sordan (INIA) were inoculated with spores and mycelia of mycorrhiza and maintained for three months in a sand:vermiculite:peat (1:1:1; v:v:v) substrate for its propagation. Then, colonized roots and substrate were used as inocula (Durán et al., 2013).

\subsubsection{Pathogen inocula preparation}

A highly pathogenic isolate of Gaeumannouyces graminis was used as inoculum inoculation. For this, oat kernel inoculum was prepared. Colonized oat were blended, sieved to a particle size of $0.5-1.0 \mathrm{~mm}$, and stored at $5^{\circ} \mathrm{C}$ until use (Duran et al., 2017).

\subsection{Greenhouse assay 1}

A completely randomized experimental design was adopted. Wheat seeds cv Fritz were surface-disinfected by dipping in $0.8 \%$ (v:v) $\mathrm{NaClO}$ solution for $15 \mathrm{~min}$. Then, seeds were placed in a pot containing $1 \mathrm{~kg}$ of soil from Maquehue belonging to Freire series (Table 1). For AMF incolated plants, pots including AMF inoculum:soil (1:1) were used. After 7 days, the bacteria inoculum was directly injected into the rhizosphere of wheat with two millilitres of $10^{9} \mathrm{CFU} \mathrm{mL} \mathrm{m}^{-1}$ of each strain grown in selenite, for the consortia preparation the same number of cell of both bacteria were considered. The treatments were as follows: (1) control, (2) Acinetobacter sp.E6.2, (3) Acinetobacter sp.E6.2 grown in selenite, (4) Bacillus sp.E5, (5) Bacillus sp.E5 grown in selenite, (6) consortium (Acinetobacter sp. + Bacillus sp.), and (7) consortium grown in selenite. These treatments were applied to both AMF inoculated (with Claroideoglomus claroideum) and non-AMF inoculated pots at 14 and 30 days, thus we considered a total of 14 treatments. Plants were irrigated every 10 days with Taylor and Foy nutrient solution (Taylor and Foy, 1985) and maintained for 4 months under greenhouse conditions at day/night cycle of $16 / 8 \mathrm{~h}, 21 / 15^{\circ} \mathrm{C}$ and $50 \%$ relative humidity.

Mycorrhizal colonization in root plants was measured by using $10 \% \mathrm{KOH}$ and staining with $0.05 \%$ Trypan blue in lactic acid (v/v) and was quantified according to the grid-line intersect method (Giovannetti and Mosse, 1980). In addition, colonized roots were observed by using an Olympus CX31 optical microscope.

\subsection{Antioxidant activity determination}

Enzymatic extracts were obtained according to Lin et al., (2009). Total protein concentration was determined by the Coomassie blue G-250 dye-binding assay, using bovine serum albumin as a standard (Bradford, 1976). 
Table 1. Chemical parameters of the Maquehue soil (Freire series) used in the assay.

\begin{tabular}{|c|c|}
\hline Variable & Value \\
\hline $\mathrm{N}\left(\mathrm{mg} \mathrm{kg}^{-1}\right)$ & 29 \\
\hline $\mathrm{P}\left(\mathrm{mg} \mathrm{kg}^{-1}\right)$ & 27 \\
\hline $\mathrm{K}\left(\mathrm{mg} \mathrm{kg}^{-1}\right)$ & 344 \\
\hline pH (water 1:5, w:v) & 5.75 \\
\hline Organic Matter (\%) & 17 \\
\hline $\mathrm{K}\left(\mathrm{cmol}^{+} \mathrm{kg}^{-1}\right)$ & 0.88 \\
\hline $\mathrm{Na}\left(\mathrm{cmol}^{+} \mathrm{kg}^{-1}\right)$ & 0.15 \\
\hline $\mathrm{Ca}\left(\mathrm{cmol}^{+} \mathrm{kg}^{-1}\right)$ & 7.61 \\
\hline $\mathrm{Mg}\left(\mathrm{cmol}^{+} \mathrm{kg}^{-1}\right)$ & 1.77 \\
\hline $\mathrm{Al}\left(\mathrm{cmol}^{+} \mathrm{kg}^{-1}\right)$ & 0.05 \\
\hline Al sat (\%) & 0.48 \\
\hline $\operatorname{CICE}\left(\mathrm{cmol}^{+} \mathrm{kg}^{-1}\right)$ & 10.46 \\
\hline Bas. sat $\left(\mathrm{cmol}^{+} \mathrm{kg}^{-1}\right)$ & 10.41 \\
\hline
\end{tabular}

\subsubsection{Superoxide dismutase activity (SOD)}

The activity of SOD was assayed spectrophotometrically by measuring its ability to inhibit the photochemical reduction of nitroblue-tetrazolium (NBT) (Medha et al. 2013). A set of cuvettes was covered with a black cloth as a control. The other set was placed approximately $30 \mathrm{~cm}$ below a bank of two $15-\mathrm{W}$ fluorescent lamps. The reaction was initiated by turning the light on for $10 \mathrm{~min}$. Following light exposure, the tubes were covered (Abassi et al., 1998). One enzyme unit was defined as the amount of free extract that inhibited the reduction of nitrobluetetrazolium by $50 \%$ at $\mathrm{pH} 7.0$. The total specific enzyme activity was expressed as $\mathrm{U}$ mg protein ${ }^{-1}$. The scavenging ratio of samples was expressed as Trolox equivalents per gram of plant samples (Wong et al., 2006). Thus, $0.1 \mathrm{~g}$ of vegetal material (wheat shoot) was homogenized with methanol. Then, $0.25 \mathrm{~mL}$ of samples were mixed with $0.75 \mathrm{~mL}$ of $0.25 \mathrm{mM} \mathrm{DPPH}$ ethanol. The reaction mixture $(1 \mathrm{~mL})$ was added to the automatic injector Synergy ${ }^{\mathrm{TM}}$ HT multimode mi- croplate reader. The DPPH solution absorbance was measured at $517 \mathrm{~nm}$.

\subsection{Total Se determination}

For Se determination, two phenological steps were considered. The first step was at 30 days after seedling, when plants were in the middle tillering, and the second step was at 4 months (dry grain). The Se content was measured by Atomic Absorption Spectrophotometry (AAS) with an HG 3000 Hydride generator (GBC Scientific Equipment Ltd.) using $\mathrm{NaBH}_{4}$ solution as the reducing agent (Kumpulainen, 1983). Two Se-enriched flour samples supplied by the Department of Applied Chemistry and Microbiology of Helsinki University (Finland) were used for reference.

2.5. NanoSe penetration in plants analysed by transmission electron microscopy (TEM)

As the main Se form found in the inocula was $\mathrm{Na}$ noSe (Durán et al., 2015), the ability of NanoSe 
to penetrate cell walls was visualized by highmagnification TEM (model JEOL/JEM 1200 EX II) using root collected from plants with and without exposure to Se (Dhanjal and Cameotra, 2010). Ultra-thin sections were cut using an ultra-microtome, and the sections were stained with alcoholic uranyl acetate (saturated solution in ethanol) for 2 min and subsequently stained in lead citrate for 2 min before examining the grids by TEM. Plants without Se supplementation were used as controls and processed similarly.

\subsection{Fluorescent labelling of endophytic selenobacteria}

Bacillus sp.E5 and Acinetobacter sp.E6.2 were tagged by parental conjugation (Lambersten et al., 2004) with pBK-mini-Tn7-gfp (pUC19-derived delivery vector for mini-Tn7-gfp, gentamycin resistant, chloramphenicol acetyltransferase, $\beta$-lactamase, $\mathrm{Mob}^{+}$, Koch et al., 2001) and the helper plasmid pUX-BF13 (donor of $\mathrm{Tn} 7$ transposase tns $A B C D E \mathrm{R} 6 \mathrm{~K}$, ampicillin resistant, $\beta$-lactamase, $\mathrm{Mob}^{+}$, Bao et al., 1991). Bacteria were grown on Luria-Bertani (LB) medium containing gentamycin as antibiotic $\left(10 \mu \mathrm{g} \mathrm{mL}^{-1}\right)$.

\subsection{Confocal laser scanning microscopy}

The ability of bacteria to colonize the roots of wheat plants was checked by confocal laser scanning microscopy (CLSM). For this purpose, wheat plants were growth in soil from Maquehue (Table 1) and 5 $\mathrm{mL}$ of $10^{9} \mathrm{CFU} \mathrm{mL} \mathrm{m}^{-1}$ grown in LB were inoculated in each pot at 7 days. The inoculum was injected into the rhizosphere of wheat. The treatments were: (1) control (non inoculated), (2) Acinetobacter sp.E6.2, (3) Bacillus sp.E5, and (4) consortium (Acinetobacter sp. + Bacillus sp.). Then, roots were carefully washed and the presence of tagged bacteria was confirmed by the CLSM Olympus Fluoview 1000.

\subsection{Biocontrol greenhouse assay 2}

In order to evaluate the capacity of biocontrol against Gaeumannonyces graiminis of microbial inoculant using in this study another assay using substrate sand:vermiculite:peat $(1: 1: 1)$ to avoid the effect of soil was made. The treatments were 1) control, (2) Acinetobacter sp.E6.2, (3) Bacillus sp.E5 and consortium (Acinetobacter sp. $+\mathrm{Ba}$ cillus sp.). These treatments were applied to both AMF inoculated (with Claroideoglomus claroideum) and non-AMF inoculated pots and with Ggt and without Ggt, thus we considered a total of 14 treatments. All treatments in triplicates.

Briefly, experiment was conducted in pots filled with $80 \mathrm{~g}$ of sterile soil $\left(121^{\circ} \mathrm{C} 15 \mathrm{~min}\right.$, for 3 days), wheat seedlings var. Fritz were superficially disinfected and pre-germinated as previously described. Wheat plants, CV Fritz were watered each three days and nutrient Taylor and Foyd solution was applied each 15 days. Plants were grown in greenhouse conditions and collected after 45 days. Then, the percentage of root blackening against a white background, on a $0-100 \%$ scale, was recorded. Shoots carefully separated to roots and dried at $70{ }^{\circ} \mathrm{C}$ for $72 \mathrm{H}$ to obtain the shoot dry weight

\subsection{Statistical analysis}

Data sets were analysed by one-way analysis of variance (ANOVA), and mean comparisons were performed using Tukey's multiple range test with the SPSS software (SPSS, Inc.). All experiments were performed in triplicate, and the values were given as the means $\pm \mathrm{SE}$. Differences were considered to be significant when the $P$ value was less than or equal to 0.05 . 


\section{Results}

\subsection{Plant growth}

The roots of wheat plants inoculated with Acinetobacter sp.E6.2, particularly when Se was supplemented, showed higher growth than plants of other treatments (Figure 1). No significant differences were found in plants inoculated with Bacillus sp.E5 compared with the control plants in all treatments. Wheat plants were effectively colonized by the mycorrhizal inoculum (from 40 to $54 \%$ ) but this colonization reduced radical growth significantly in control plants and plants inoculated with Acinetobacter sp.E6.2. However, no significant differences in shoot yield were found between mycorrhizal and non-mycorrhizal plants.

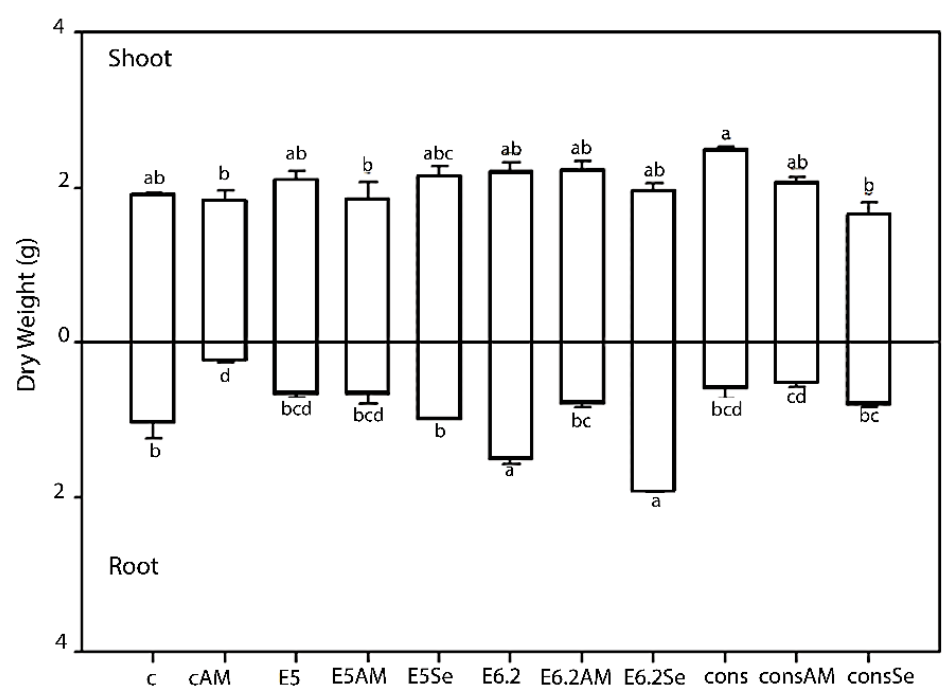

Figure 1. Dry weight (g) of shoots and roots of wheat plants inoculated with endophytic bacteria (Bacillus sp.E5 or Acinetobacter sp.E6.2 and dual consortia) and the arbuscular mycorrhizal fungus (AM) Claroideoglomus claroideum, supplemented or not with Se. Tukey's post-hoc test was used to compare treatment means. Values followed by the same letter do not differ at $\mathrm{P} \leq 0.05(\mathrm{n}=3)$. Bars denote means \pm S.E. c (control), cAM (control+mycorrhiza), E5 (Bacillus sp.E5), E5AM (Bacillus sp.E5+mycorrhiza), E5Se (Bacillus sp.E5+selenium), E6.2 (Acinetobacter sp.E6.2), E6.2AM (Acinetobacter sp.E6.2+mycorrhiza), E6.2Se (Acinetobacter sp.E6.2+selenium), Cons (consortia), ConsAM (consortia+mycorrhiza), ConsSe (consortia+selenium).

\subsection{Antioxidant activity}

Higher SOD activity was found in the shoots of plants inoculated with both bacteria, mainly in mycorrhizal plants supplemented with Se respect to the rest of treatments. No significant differences between noninoculated and inoculated plants (Figure 2a) were observed for SOD of roots. Plants inoculated with Se-supplemented bacteria, either Acinetobacter or Bacillus, showed higher DPPH activity in both shoots 
and roots than the control plants (Figure 3b). The lowest DPPH activities were observed in roots and shoots of plants inoculated with only Acinetobacter
sp.E6.2, without Se (Figure 2b), this activity was improved by AM colonization for this treatment.
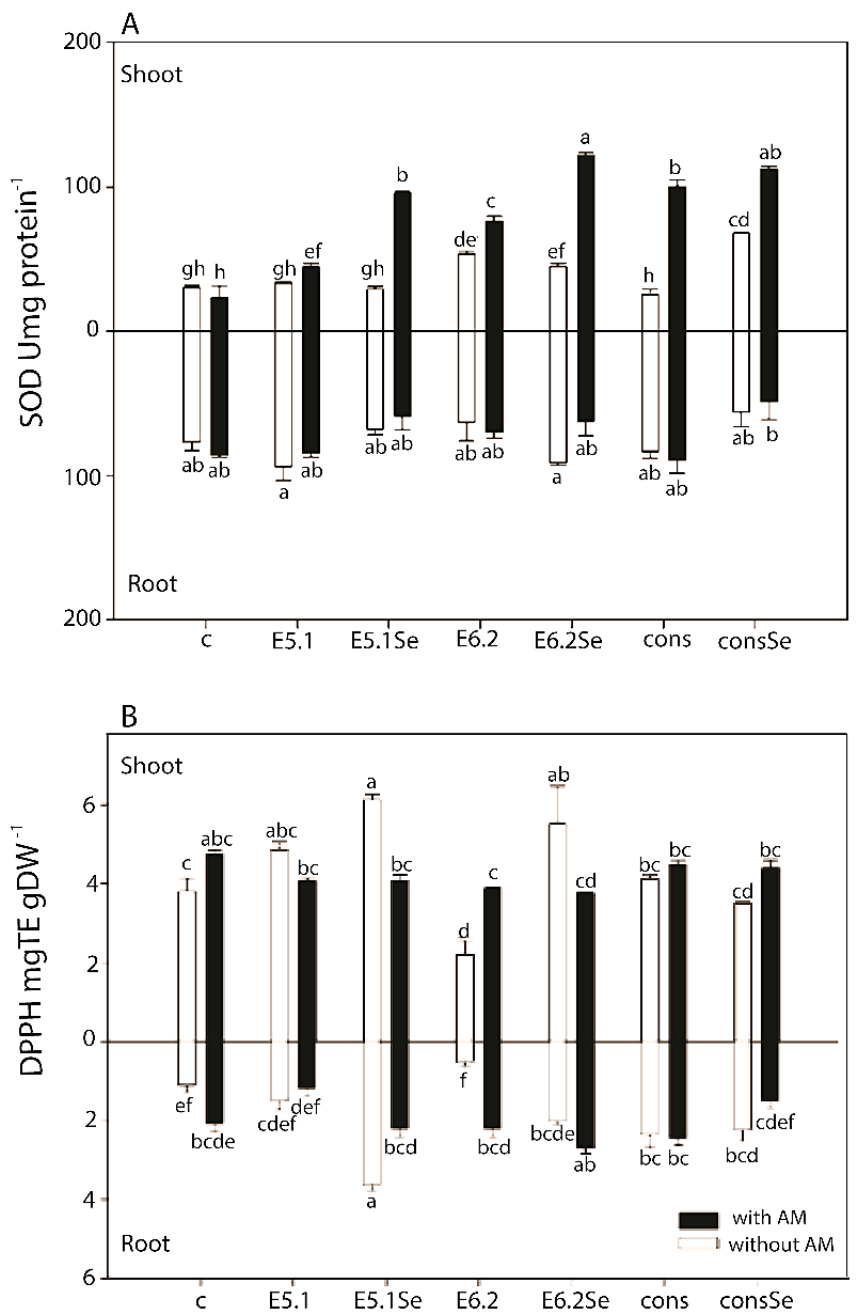

Figure 2. (A) Superoxide dismutase and (B) $\alpha, \alpha$-diphenyl- $\beta$-picrylhydrazyl-radical activity in shoots and roots of wheat plants inoculated with endophytic bacteria (Bacillus sp.E5 or Acinetobacter sp.E6.2 and dual consortia) and the arbuscular mycorrhizal fungus (AM) Claroideoglomus claroideum, supplemented or not with Se. Tukey's post-hoc test was used to compare treatment means. Values followed by the same letter do not differ at $\mathrm{P} \leq 0.05$ $(\mathrm{n}=3)$. Bars denote means \pm S.E. c (control), E5 (Bacillus sp.E5), E5Se (Bacillus sp.E5+selenium), E6.2 (Acinetobacter sp.E6.2), E6.2Se (Acinetobacter sp.E6.2+selenium), Cons (consortia), ConsSe (consortia+selenium). 


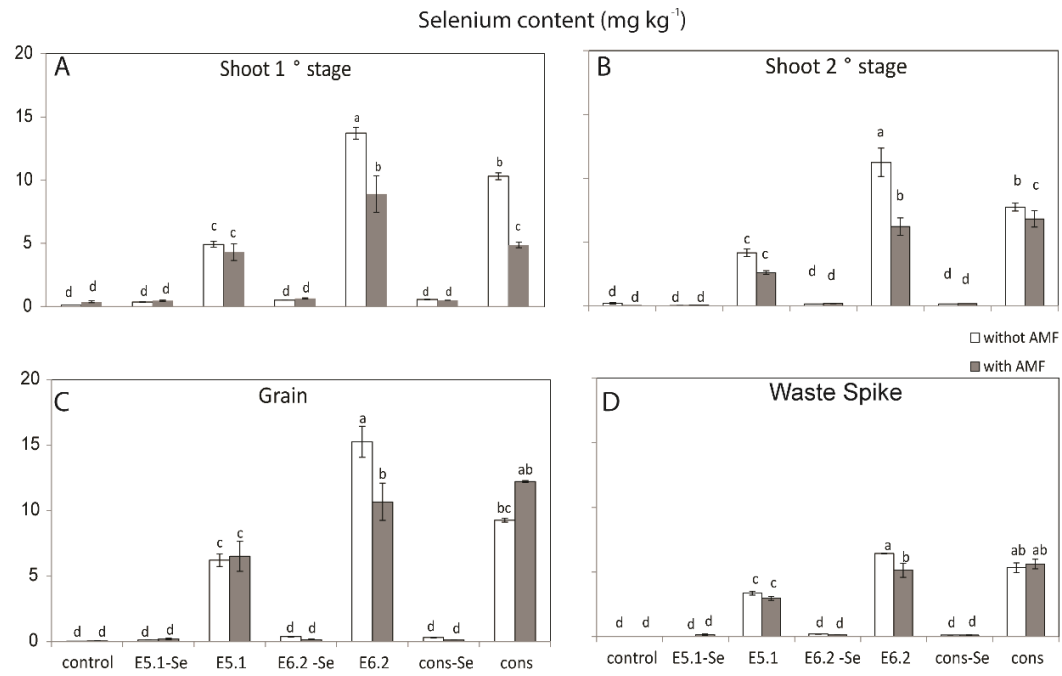

Figure 3. Se content in (A) wheat shoots at stage 1 (tillering), (B) wheat shoots at stage 2 (mature grain), (C) dry grain and (D) waste spikes of plants inoculated with endophytic bacteria (Bacillus sp.E5 or Acinetobacter sp.E6.2 and dual consortia) and AM, supplemented or not with Se. Tukey's post-hoc test was used to compare treatment means. Values followed by the same letter do not differ at $P \leq 0.05$. Bars denote means \pm S.E.

\subsection{Total selenium content}

In general, mycorrhizal plants showed lower Se content in the shoots than non-mycorrhizal plants, whereas no significant differences were found in grain, except in plants inoculated with Acinetobacter sp., where major Se content was observed in non-mycorrhizal plants (Figure 3c). Higher Se content was observed in shoots of plants inoculated with Acinetobacter sp.E6.2 than in those inoculated with Bacillus sp.E5 in both stages, at 30 days (tillering) and 4 months (mature grain). Shoots and grains showed similar tendencies with regard to $\mathrm{Se}$ concentration (Figure 3a, 3b, 3c). Thus, at both tillering and mature grain, a positive and significant correlation between Se concentration in shoots of plants was found $(\mathrm{R}=0.420 ; P<0.05$ and $\mathrm{R}=0.744$;
$P<0.01$ ), and we also observed a positive correlation regarding Se content between grain and waste spikes (Figure $3 \mathrm{~d}, \mathrm{R}=0.877 ; P<0.01$ ).

3.4 NanoSe penetration into plant cells analysed by transmission electron microscopy (TEM)

Differences in NanoSe size $(\sim 20-200 \mathrm{~nm})$ were observed in the lyophilized powder of bacteria inocula (Figure $4 a, b$ ). We found NanoSe inside and scattered around the cells, both as free deposits and as aggregates attached to the bacterial cell mass in Se supplemented plants (Figure $5 \mathrm{c}, \mathrm{d}$ ), but no in plants without Se treatments (Figure 4e). Moreover, the electron diffraction patterns of single $\mathrm{Na}$ noSe particles confirmed the occurrence of amorphous Se in lyophilized selenobacteria (Figure 4a). 

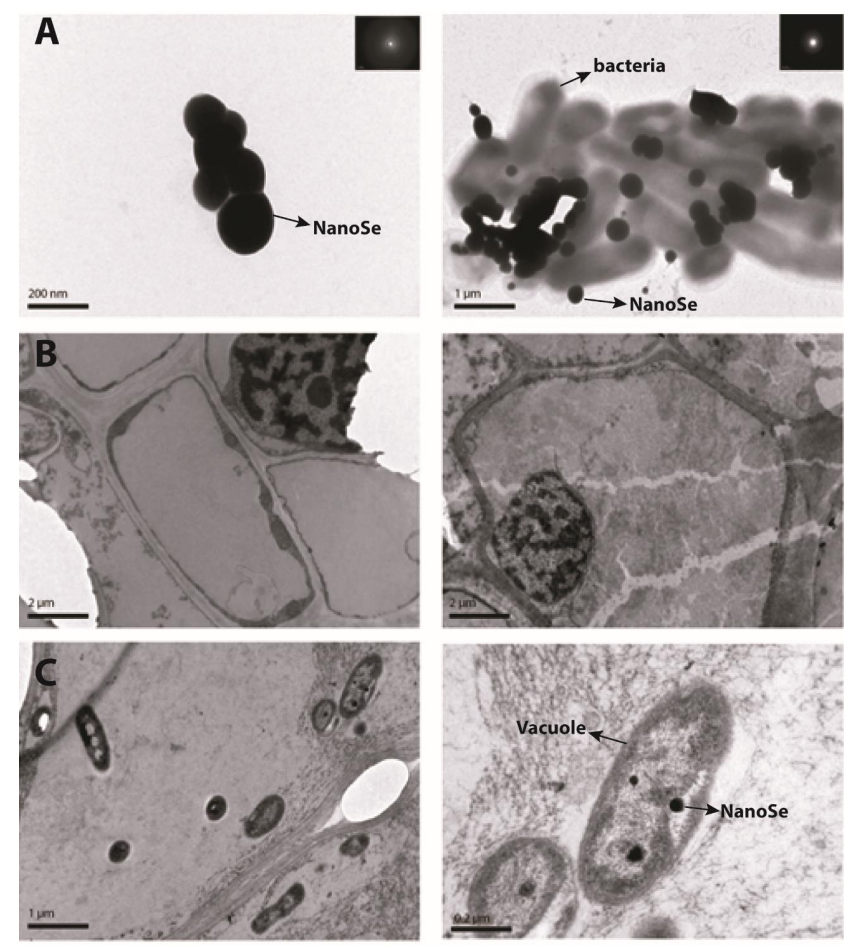

Figure 4. Transmission electron microscopy images of (A) bacteria supplemented with Se biosynthesized as elemental nanospheres, (B) root cells of wheat seedlings without Se supplementation and (C) vacuoles from root cell of Se-supplemented wheat. Micrographs were taken after 10 days of bacterial inoculation.
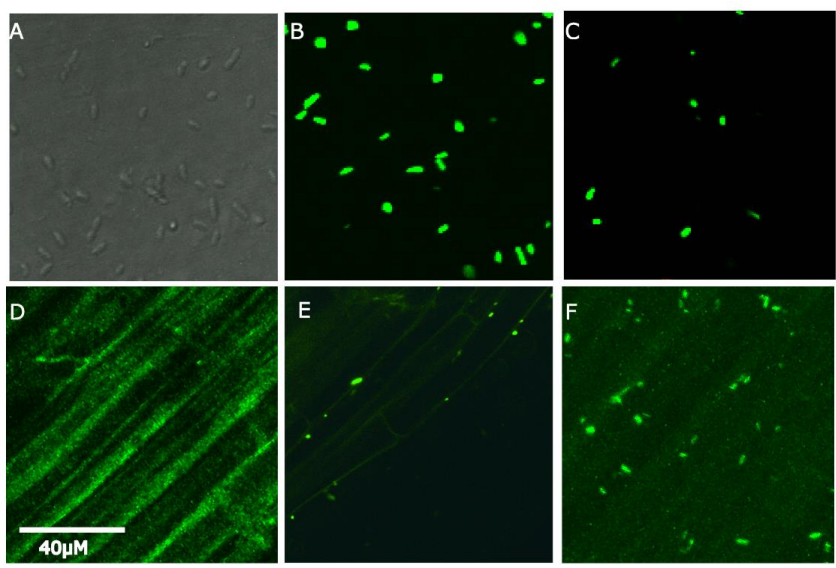

Figure 5. Confocal laser scanning microscopy images of endophytic colonization: (A) control bacteria without GFP tag, (B) GFP-tagged Bacillus sp.E5, (C) GFP-tagged Acinetobacter sp.E6.2, (D) roots of wheat plants without bacterial colonization, (E) roots of wheat plants colonized by GFP-tagged Bacillus sp.E5 and (F) roots of wheat plants colonized by GFP-tagged Acinetobacter sp.E6.2. 


\subsection{Colonization of wheat root by Green Fluorescent} Protein (GFP)-tagged endophytic selenobacteria

Bacillus sp.E5 and Acinetobacter sp.E6.2 strains were successfully tagged with the mini-Tn7 system using the parental conjugation method. LB selective agar plates were used to grow typical colonies of both strains. Green fluorescence emission was observed by confocal laser scanning microscopy (Figure 5b, c), whereas in bacteria without GFP-tagged (control) was not detected fluorescence emission (Figure 5a). Bacterial detection of wheat roots by GFP-tagged Bacillus sp.E5 and Acinetobacter sp.E6.2 strains occurred as shown by the comparison with plants inoculated with bacteria without the mini-Tn7 plasmid (Figure 5e, f).

\subsection{Biocontrol effect of microbial inocula against} Gaeumannonyces graminis

In general, plants infection by the root pathogen $\mathrm{Geu}$ mannomyces graminis reduced growth of wheat plants (Table 1). According to our results both bacteria (Bacillus sp.E5 and Acinetobacter sp.E6.2 strains) diminish the incidence of disease caused by Gaeumannonyces graminis (Table 2) observed by the blackening roots. This effect was more evident in plants inoculated with Acinetobacter sp.E6.2 than Bacillus sp.E5. Similar behaviour in plant inoculated with the consortia (Bacillus sp.E5 + Acinetobacter sp.E6.2) was found. However, no effect in mycorrhizal plants in terms of disease diminution was observed. Despite plants inoculated with mycorrhiza in general showed major biomass production.

Table 2. Biocontrol assay against Gaeumannomyces gramini var tritici

\begin{tabular}{|c|c|c|c|c|c|c|c|c|}
\hline \multicolumn{9}{|c|}{ Leaf } \\
\hline \multirow{3}{*}{ Factor } & \multicolumn{4}{|c|}{ RB867515 } & \multicolumn{4}{|c|}{ RB92579 } \\
\hline & \multicolumn{2}{|c|}{ w/o-Mo } & \multicolumn{2}{|c|}{ w-Mo } & \multicolumn{2}{|c|}{ w/o-Mo } & \multicolumn{2}{|c|}{ w-Mo } \\
\hline & w/o- & w- & w/o- & W- & w/o- & w- & w/o- & W- \\
\hline \multicolumn{9}{|l|}{ DAP } \\
\hline 70 & 0.66 & 0.60 & 0.82 & 0.91 & 0.74 & 0.73 & 0.96 & 1.06 \\
\hline 100 & 0.37 & 0.37 & 0.43 & 0.40 & 0.36 & 0.38 & 0.44 & 0.45 \\
\hline 130 & 0.28 & 0.55 & 0.64 & 0.56 & 0.29 & 0.29 & 0.37 & 0.44 \\
\hline 200 & 0.68 & 0.82 & 0.96 & 0.93 & 0.77 & 0.78 & 0.83 & 1.06 \\
\hline 365 & 0.40 & 0.29 & 0.45 & 0.43 & 0.40 & 0.36 & 0.56 & 0.53 \\
\hline Mean N & 0.48 & 0.53 & 0.66 & 0.65 & 0.51 & 0.51 & 0.63 & 0.71 \\
\hline Mean Mo & \multicolumn{2}{|c|}{$0.50 \mathrm{~b}$} & \multicolumn{2}{|c|}{$0.65 \mathrm{a}$} & \multicolumn{2}{|c|}{$0.51 \mathrm{~b}$} & \multicolumn{2}{|c|}{$0.67 \mathrm{a}$} \\
\hline Mean & \multicolumn{4}{|c|}{$0.58 \mathrm{a}$} & \multicolumn{4}{|c|}{$0.59 \mathrm{a}$} \\
\hline \multicolumn{9}{|c|}{ Roots } \\
\hline \multirow{3}{*}{ Factor } & \multicolumn{4}{|c|}{ RB867515 } & \multicolumn{4}{|c|}{ RB92579 } \\
\hline & \multicolumn{2}{|c|}{ w/o-Mo } & \multicolumn{2}{|c|}{ w-Mo } & \multicolumn{2}{|c|}{ w/o-Mo } & \multicolumn{2}{|c|}{ w-Mo } \\
\hline & w/o- & w- & w/o- & W- & w/o- & w- & w/o- & w- \\
\hline DAP & & \multicolumn{3}{|c|}{$-\mathrm{mg} \mathrm{kg}^{-1}$} & \\
\hline 70 & 0.98 & 1.15 & 1.30 & 1.26 & 0.79 & 0.76 & 1.13 & 1.16 \\
\hline 100 & 0.63 & 1.08 & 0.79 & 1.43 & 0.73 & 0.89 & 0.93 & 1.05 \\
\hline 130 & 0.99 & 1.05 & 1.21 & 1.00 & 0.69 & 0.83 & 0.49 & 1.13 \\
\hline 200 & 1.07 & 0.74 & 0.92 & 0.78 & 0.84 & 0.80 & 1.25 & 0.93 \\
\hline 365 & 0.81 & 0.63 & 0.85 & 0.75 & 0.48 & 0.70 & 0.70 & 0.90 \\
\hline Mean N & 0.90 & 0.93 & 1.01 & 1.04 & 0.71 & 0.80 & 0.90 & 1.03 \\
\hline Mean Mo & \multicolumn{2}{|c|}{$0.91 \mathrm{~b}$} & \multicolumn{2}{|c|}{$1.03 \mathrm{a}$} & \multirow{2}{*}{\multicolumn{3}{|c|}{$\begin{array}{ll}0.75 \mathrm{~b} & \\
& 0.86 \mathrm{~b}\end{array}$}} & $7 \mathrm{a}$ \\
\hline Mean & & & & & & & & \\
\hline
\end{tabular}

Tukey's post-hoc test was used to compare treatment means between columns. Values followed by the same letter do not differ at $P \leq 0.05(\mathrm{n}=3)$. Bars denote means \pm S.E 


\section{Discussion}

Recent studies showed that inocula based on Acinetobacter sp. strain E6.2 and Bacillus sp. strain E5 were able to metabolize the most important organic Se forms as SeMet and SeMeSeCys for cancer prevention and elevated NanoSe (Durán et al., 2015). In this study, wheat plants inoculated with Acinetobacter sp. showed higher root growth, which can be attributed to the better colonization ability of this strain compared to root colonization by Bacillus sp. strain. No effect in plant yield in AMF-inoculated plants was found, even though the interactions between AMF and bacteria, particularly rhizobacteria, are commonly synergistic, mainly with Gram $(+)$ bacteria (Artursson et al., 2005). Thus, studies realized by Sundram et al. (2011) showed that endophytic bacteria promoted de AMF spore formation and hyphal length. However, certain bacteria can be influenced by AMF exudates and plant nutrition status (Artursson et al., 2006). In semiarid environments, studies showed that the colonization ability and community composition of endophytic bacteria and endophytic fungi can influence the colonization and community composition of AMF (Taniguchi et al., 2012).

Mycorrhizal plants supplemented with Se showed higher SOD production in shoots compared with non-mycorrhizal plants, as previously suggested (Ruiz-Lozano et al., 1996). This result could be attributed to the enhancement production of superoxide radicals by mycorrhizal symbiosis (Arines et al., 1994). No effect of Se application was found. In contrast to inorganic Se where up to $2 \mu \mathrm{M}$ decreased SOD activity in Al-stressed plants (Cartes et al., 2010). However, major DPPH radical scavenging activity was observed in plants inoculated with both bacteria and treated with Se. Probably as the result of the increase in the antioxidant defence system due to the Se supply (Xu et al. 2003). Similarly, studies reported major DPPH scavenging activity by NanoSe (Barnaby et al., 2011), the main Se form in our inocula (data not shown). These amorphous NanoSe structures, characteristic of elemental selenium obtained by biologic reduction (Torres et al. 2012) were observed in the roots of Se treated wheat plants, mainly in vacuoles (Figure 4), as previously reported (Parsons et al., 2010). However, only the NanoSe particles not bigger than $20 \mathrm{~nm}$ in diameter entered into plants, supporting our previous hypothesis that most of the NanoSe particles did not pass through the cell wall pores due to their large size (Durán et al., 2015). Thus, the size of NanoSe is an important for Se biofortification using bacteria. A further support of this hypothesis is the presence of magnetic carbon-coated nanoparticles in the vascular tissues of wheat plants (Cifuentes et al., 2010).

Se content was evaluated at tillering and mature grain. At both stages there were positive correlations of Se content in the shoots and the grain. Shoots of Sesupplemented plants showed between 5 and $15 \mathrm{mg}$ Se $\mathrm{kg}^{-1}$, whereas shoot of plants inoculated with rhizo-

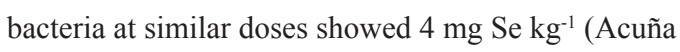
et al., 2013). Thus, endophytic bacteria strains seem to be more efficient than rhizobacteria for Se biofortification, probably because acted as effective biotechnological carriers for Se augmentation inside the plant because bacteria can incorporate NanoSe into the cells (Acuña et al., 2013), similar to the behaviour of endophytic bacteria used for the bioaugmentation of trace elements (Sessitsch et al., 2013).

The construction of $g f p$-tagged endophytic selenobacteria demonstrated that Bacillus sp.E5 and Acinetobacter sp.E6.2 strains can form endophytic populations in roots. Other authors reported that the mini-Tn7 system forms stable genomic islands in a variety of bacteria (Koch et al., 2001), including Bacillus sp., which is reported to have the attTn7 site (Parks and Peters, 2007). Thus, GFP-labelling seems to be a useful tool 
for studying microbe-plant interactions (Ryan et al., 2008). However, is important to consider that GFP genes produce pleiotropic changes attributable to stress protein synthesis (Rodriguez et al., 2006).

Respect to the capacity of biocontrol against Gaeumannopmyces graminis, no effect in mycorrhizal plants in terms of root infection decline was found, in contrast to previous studies realized by Behn (2008) and Castellanos-Morales et al. (2012), where mycorrizal plant was able to inhibit the pathogen infection. However, mycorrhizal plants resulted in an increase in dry matter biomass in Gaeumannomyces graminis infected wheat similar to reported by Behn (2008). In relation to bacteria inocula we found that both endophytic bacteria (Acinetobacter sp. E6.2 and Bacillus sp. E5) were able to diminish efficiently the pathogen incidence, mainly Acinetobacter sp. E6.2. Similar to the in vitro assay realized by Duran et al., 2014 with the same strains corroborating the hypothesis that the inocula promote the plant growth and protect against take-all in greenhouse.

\section{Conclusions}

Our results showed the feasibility of the use of endophytic bacteria and AMF inocula in consortium as a biofortification strategy due to $i$ ) effective root colonization, ii) improvement of antioxidant activity, iii) increased $\mathrm{Se}$ content in the grain of wheat plants and iv) Gaeumannomyces graminis biocontrol as a potential tool to generate Se-biofortified flour for human consumption and diminish the incidence of the main pathogen that affect the most important cereal of southern Chile.

\section{Acknowledgements}

This study was supported by the Comisión Nacional de Investigación Científica y Tecnológica (CONICYT), FONDECYT Postdoctoral Project N 3130542 and FONDECYT Iniciation Project No. 11150540 from Chilean Government. The authors acknowledge the important contributions of Susana García and the technical support of the Scientific and Technological Bioresource Nucleus (BIOREN) from La Frontera University.

\section{References}

Abassi, N.A., Kushad, M.M., Endress, A.G. 1998. Active oxygen-scavenging enzymes activities in developing apple flowers and fruits. Scientia Horticulturae Amsterdam. 3, 183-194.

Acuña, J.J., Jorquera, M.A., Barra, P.J., Crowley, D.E., Mora, M.L. 2013. Selenobacteria selected from the rhizosphere as a potential tool for Se biofortification of wheat crops. Biology and Fertility of Soils. 49, 175-185.

Arines, J., Quintela, M., Vilariñ, A., Palma, J.M. 1994. Protein patterns and superoxide dismutase activity in non-mycorrhizal and arbuscular mycorrhizal Pisum sativum L. plants. Plant and Soil. $166,37-45$.

Artursson, V., Finlay, R.D., Jansson, J.K. 2005. Combined bromodeoxyuridine immunocapture and terminal-restriction fragment length polymorphism analysis highlights differences in the active soil bacterial metagenome due to Glomus mosseae inoculation or plant species. Environmental Microbiology. 7, 1952-1966.

Artursson, V., Finlay, R.D., Jansson, J.K. 2006. Interactions between arbuscular mycorrhizal fungi and bacteria and their potential for stimulating plant growth. Environmental Microbiology. 8, $1-10$.

Bao, Y., Lies, D.P., Fu, H., Roberts, G.P. 1991. An improved Tn7-based system for the single-copy insertion of cloned genes into chromosomes of Gram-negative bacteria. Gene. 109, 167-168. 
Barnaby, S.N., Frayne, S.H., Fath, K.R., Banerjee, I.A. 2011. Growth of Se Nanoparticles on Kinetin Assemblies and their Biocompatibility Studies. Soft Matter. 9, 313-334.

Behn, O. 2008. Influence of Pseudomonas fluorescens and arbuscular mycorrhiza on the growth, yield, quality and resistance of wheat infected with Gaeumannomyces graminis. Journal of Plant Diseases and Protection. 115, 4-8.

Bradford, M.M. 1976. A rapid and sensitive method for the quantitation of microgram quantities of protein utilizing the principle of protein-dye binding. Analytical Biochemistry. 72, 248-274.

Cartes, P., Gianfreda, L., Mora, M.L. 2005. Uptake of Selenium and its Antioxidant Activity in Ryegrass When Applied as Selenate and Selenite Forms. Plant and Soil. 276, 359-367.

Cartes, P., Jara, A.A., Pinilla, L., Rosas, A., Mora, M.L. 2010. Selenium improves the antioxidant ability against aluminium-induced oxidative stress in ryegrass roots. Annals of Applied Biology. 156, 297-307.

Castellanos-Morales, V., Cárdenas-Navarro, R., García-Garrido, J. M., Illana, A., Ocampo, J.A., Steinkellner, S., Vierheilig, H. 2012. Bioprotection against Gaeumannomyces graminis in barley - A comparison between arbuscular mycorrhizal fungi. Plant, Soil and Environment. 58, 256-261.

Cifuentes, Z., Custardoy, L., de la Fuente, J.M., Marquina, C., Ibarra, M.R., Rubiales, D., Pérezde-Luque, A. 2010. Absorption and translocation to the aerial part of magnetic carbon-coated nanoparticles through the root of different crop plants. Journal of Nanobiotechnology. 8, 26.

Dhanjal, S., Cameotra, S.S. 2010. Aerobic biogenesis of selenium nanospheres by Bacillus cereus isolated from coalmine soil. Microbial Cell Factories. 9,52 .
Durán, P., Acuña, J.J., Jorquera, M.A., Azcón, R., Borie, F., Cornejo, P., Mora, M.L. 2013. Enhanced selenium content in wheat grain by co-inoculation of selenobacteria and arbuscular mycorrhizal fungi: A preliminary study as a potential Se biofortification strategy. Journal of Cereal Science. 57, 275-280.

Durán, P. Acuña, J.J., Jorquera, M.A., Azcón, R., Paredes, C., Rengel, Z., Mora, M.L. 2014. Endophytic bacteria from selenium-supplemented wheat plants could be useful for plant-growth promotion, biofortification and Gaeumannomyces graminis biocontrol in wheat production. Biology and Fertility of Soils. 50, 983-990.

Durán, P., Acuña, J.J., Gianfreda, L., Azcón, R., Funes-Collado, V., Mora, ML. 2015. Endophytic selenobacteria as new inocula for selenium biofortification. Applied Soil Ecology. 96, 319-326.

Durán, P., Jorquera, M., Viscardi, S., and Carrion, V. J. (2017). Screening and Characterization of Potentially Suppressive Soils against Gaeumannomyces graminis under Extensive Wheat Cropping by Chilean Indigenous Communities. Frontiers in Microbiology. 8, 1-16.

Duran, P., Tortella, G., Viscardi, S., Barra, P. J., Carrion, V. J., Mora, M. L., Pozo, M. 2018. Microbial Community Composition in Take-All Suppressive Soils. Frontiers in Microbiology. 9, 1-15.

Giovannetti, M., Mosse, B. 1980. Evaluation of techniques for measuring vesicular arbuscular mycorrhizal infection in roots. New Phytologist. 84, 489-500.

Govasmark, E., Salbu, B. 2011. Translocation and re-translocation of selenium taken up from nutrient solution during vegetative growth in spring wheat. Journal of the Science of Food and Agriculture. 91, 1367-1372. 
Koch B., Jensen, L.E., Nybroe, O. 2001. A panel of Tn7-based vectors for insertion of the gfp marker gene or for delivery of cloned DNA into Gram-negative bacteria at a neutral chromosomal site. Journal of Microbiological Methods. 45, 187-195.

Kumpulainen, J., Raittila, A.M., Lehto, J., Koivistoinen, P. 1983. Electrothermal atomic absorption spectrometric determination of selenium in foods and diets. Journal of the Association of Official Analytical Chemists. 66, 1129-1135.

Lin, X., Xu, X., Yang, C., Zhao, Y., Feng, Z., Dong, Y. 2009. Ecotoxicology and environmental safety activities of antioxidant enzymes in three bacteria exposed to bensulfuron-methyl. Ecotoxicology and Environmental Safety. 72, 1899-1904.

Lyons, G., Stangoulis, J., Graham, R. 2013. High-selenium wheat: biofortification for better health. Nutrition Research Reviews. 16, 45-60.

Mora, M.L., Pinilla, L., Rosas, A., Cartes, P. 2008. Selenium uptake and its influence on the antioxidative system of white clover as affected by lime and phosphorus fertilization. Plant and Soil. 303, 139-149.

Parks, A.R., Peters, J.E. 2007. Transposon Tn7 is widespread in diverse bacteria and forms genomic islands. Journal of Bacteriology. 5, 2170-2173.

Parsons, J., Lopez, M., Gonzalez, C., Peralta-Videa, J.R., Gadea-Torresdey, J.L. 2010. Toxicity and biotransformation of uncoated and coated nickel hydroxide nanoparticle on mesquite plants. Environmental Toxicology Chemistry. 29, 1146-1154.

Rayman, M.P. 2007. Selenium in cancer prevention: a review of the evidence and mechanism of action. Proceedings and the Nutrition Society. 64, 527-542.
Ruiz-Lozano, J.M., Azcon, R., Palma, J.M. 1996. Superoxide dismutase activity in arbuscular mycorrhizal Lactuca sativa plants subjected to drought stress. New Phytologist. 134, 327-333.

Ryan, R.P., Germaine, K., Franks, A., Ryan, D.J., Dowling, D.N. 2008. Bacterial endophytes: recent developments and applications. FEMS Microbiololy Ecology. 1, 1-9.

Sessitsch, A., Kuffner, M., Kidd, P., Vangronsveld, J., Wenzel, W.W., Fallmann, K., Puschenreiter, M. 2013. The Role of Plant-Associated Bacteria in the Mobilization and Phytoextraction of Trace Elements in Contaminated Soils. Soil Biolohy Biochemistry. 60, 182-194.

Sundram, S., Meon, S., Seman, I.A., Othman, R. 2011. Symbiotic interaction of endophytic bacteria with arbuscular mycorrhizal fungi and its antagonistic effect on Ganoderma boninense. Journal of Microbiology. 49, 551-557.

Taniguchi, T., Usuki, H., Kikuchi, J., Hirobe, M., Miki, N., Fukuda, K., Zhang, G., Wang, L., Yoshikawa, K., Yamanaka, N. 2012. Colonization and community structure of root-associated microorganisms of Sabina vulgaris with soil depth in a semiarid desert ecosystem with shallow groundwater. Mycorrhiza. 6, 419-428.

Taylor, G.J., Foyd, C.D. 1985. Mechanisms of aluminium tolerance in Triticum aestivum (wheat). I. Differential $\mathrm{pH}$ induced by winter cultivars in nutrient solutions. American Journal of Botany. 72, 695-701.

Torres, S.K., Campos, V.L., León, C.G., RodríguezLlamazares, S.M., Rojas, S.M., González, M., Smith, C., Mondaca, M.A. 2012. Biosynthesis of selenium nanoparticles by Pantoea agglomerans and their antioxidant activity. Journal of Nanoparticle Research. 14, 1236. 
Wong, S., Leong, L., Williamkoh, J. 2006. Antioxidant activities of aqueous extracts of selected plants. Food Chemistry. 99, 775-783.
Xu, J., Yang, F., Chen, L., Hu, Y., Hu, Q. 2003. Effect of Selenium on Increasing the Antioxidant Activity of Tea Leaves Harvested during the Early Spring Tea Producing Season. Journal of Agricultural and Food Chemistry. 51, 1081-1084. 